\section{Complexities associated with orthodontic services in the National Health Service}

\author{
S. Richmond ${ }^{1}$ and A. Karki ${ }^{2}$
}
IN BRIEF
- Cost-efficiency and cost-effectiveness of orthodontic provision could be improved through better procurement, skill mix and contract service management.
- Comprehensive orthodontic data associated with KPIs will enable improved contract management and provision.
- Re-adjustment of high value treatment costs in line with the national average will allow greater numbers of patients to be treated.

Aim To detail orthodontic provision in Wales. Background In 2006 the new orthodontic contract was introduced in the NHS in England and Wales. Since the introduction of the new contract there have been recent reports of inefficiencies in orthodontic provision in Wales in terms of: orthodontic provision reaching those who need it, type of orthodontic activities undertaken, who is providing orthodontic care, the relative cost-efficiency of the orthodontic services, contracting and performance management of the services and robustness of the orthodontic database. Materials and methods 2008/09 orthodontic data on contracted services were analysed. Data from the salaried services was collected through a questionnaire. Normative orthodontic treatment need was estimated from mid-year population estimates. Results In 2008/09, there were considerable inefficiencies in the orthodontic services in Wales with varied level of access by children living in 22 former local health boards, co-terminus with local authorities in Wales. Total spend on orthodontics in Wales was around $£ 12,718,370$. It was estimated that 11,539 (30\%) of 12-17-year-olds required orthodontic treatment. In 2008/09, 11,031 children received orthodontic treatment in all NHS services in Wales indicating a potential shortfall of 508 treatments. Out of 135 GDS/PDS orthodontic contracts, 27 provided no active treatment (only assessments) and 62 provided less than 50 treatments annually. Cost per units of orthodontic activity (UOA) ranged from $€ 58$ to $€ 74$. With improved contracts and efficiency, the orthodontic budget seems sufficient to meet the orthodontic need of the population. Conclusions As with any type of NHS provision, it is important that orthodontic services are competitive, highly efficient and provided on the basis of need. Performance management of orthodontic services should focus on the number of successful orthodontic treatments delivered annually. The personal dental services (PDS) orthodontic contract will need to be modified accordingly.

\section{INTRODUCTION}

The provision of orthodontics has repeatedly been of interest to politicians, healthcare providers and the public over the last 30 years with widespread debate in relation to its contribution to health and wellbeing, ${ }^{1-3}$ the proportion of the dental budget spent on orthodontics, ${ }^{4,5}$ varied access to orthodontic provision ${ }^{6,7}$ and quality of treatment outcomes. ${ }^{8-13}$

Over the last decade the cost of orthodontic treatment in the general dental services (GDS) and personal dental services

${ }^{1 *}$ Cardiff University, Applied Clinical Research and Public Health, Cardiff Dental School, University Dental Hospital, Heath Park, Cardiff CF14 4XY; 2Public Health Wales, Dental Public Health, 1st Floor Mamhilad House, Mamhilad Park Estate, Pontypool NP4 OYP

${ }^{*}$ Correspondence to: Professor Stephen Richmond Email: richmonds@cardiff.ac.uk; Tel: 02920742451

\section{Online article number E5}

Refereed Paper - accepted 28 October 2011

DOI: 10.1038/sj.bdj.2012.98

${ }^{\circledR}$ British Dental Journal 2012; 212: E5
(PDS) in England and Wales has almost tripled from $£ 87,560,728$ to an estimated $£ 258,309,180$. In $2001 / 02$, orthodontic expenditure constituted 9\% of the GDS/ PDS dental budget for England and Wales. ${ }^{4}$ In 2008/09, £108 million was spent on the GDP/PDS dental services in Wales, out of which £12.7 million was spent on orthodontics (11.7\% of the dental budget). Since it is public money, it is important to ensure that the money is spent optimally.

In 2006, local health boards (LHBs) in Wales were given the responsibility for the provision of orthodontic services in their area to meet the need of their local population. A new orthodontic contract was introduced when the believed cumbersome 'shopping list' fee-for-item system was replaced with an overall fee for orthodontic treatment. Now the contractors receive monthly payments of onetwelfth of the annual contracted value, for which the contractor undertakes case assessments, case starts, completion and retention, including repairs and outcome assessments. The size of the contract was largely based on the historical treatment pattern. The workload measures for the contract are units of orthodontic activity (UOAs) with 1 for a case assessment and 21 for a case assessment followed by a case start. Contractors are required to deliver a certain number of UOAs annually. The threshold for entry into orthodontic treatment on the basis of the Index of Orthodontic Treatment Need (IOTN) was set at dental health component of grades 4 and 5 and grade 3 with an aesthetic component of greater than 5 . In addition, practitioners would document the outcome of their treatments on a proportion of their caseload using the peer assessment rating (PAR Index). ${ }^{14-16}$

The NHS Business Services Authority (NHSBSA) Dental Services (DS) department collects the data and provides interim and 


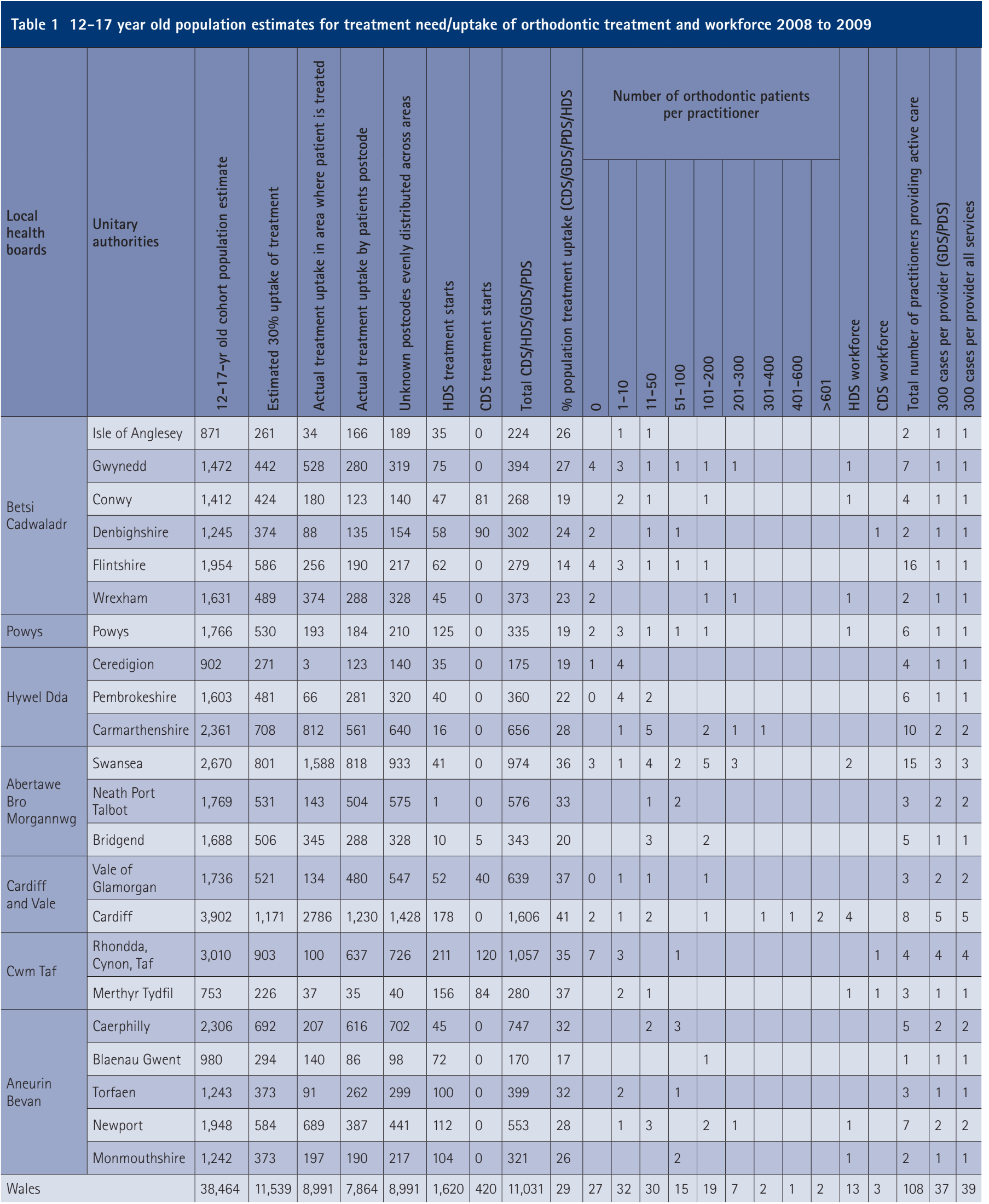

annual reports to the LHBs that manage the dental contracts. The robustness of the data depends on the forms being fully completed by all practitioners. It is a mandatory requirement for all practitioners to complete the FP170W forms. ${ }^{14-16}$
The 2003 decennial child dental health survey reported that $56 \%$ of 12-yearolds and 60\% of 15-year-old children in Wales had no orthodontic treatment need. ${ }^{17}$ The data suggested that $44 \%$ of the child population (12-15 years of age) had normative orthodontic treatment need and $32 \%$ received some form of orthodontic intervention.

Similar levels of treatment need at 12 and 15 years of age suggests there has been little impact from orthodontic 
provision, although it is recognised that treatment need for the two age groups are not recorded on the same cohort. Orthodontic treatment outcomes have been a matter of concern in the UK and recent publications have highlighted a wide discrepancy in the quality of completed treatments. ${ }^{7-12}$ Sophisticated statistical methods have enabled the formation of a robust cost-effectiveness league table to rank the orthodontic outcomes of orthodontic practitioners. ${ }^{13}$

In England and Wales orthodontic treatment can be delivered through the GDS/PDS, hospital dental services (HDS), community dental services (CDS) and through private contract. Patients can also receive orthodontic treatment from dental practitioners who have a specialist orthodontic interest (DwSI), practitioners who have a specialist orthodontic qualification, and more recently orthodontic therapists under supervision of a qualified dental practitioner.

The vast majority of orthodontic care is provided by the GDS/PDS and there appears to have been a shift in the proportions of orthodontic care provided by the different services between 1991 and 2005, with the GDS/PDS and CDS losing share and HDS gaining share (PDS/GDS $85 \%$ decreasing to $79 \%$; CDS $10 \%$ decreasing to $3 \%$; HDS $5 \%$ increasing to $16 \%$; others increasing to $2 \%) .{ }^{18,19}$ However, the data collected from the CDS and HDS are not as robust as the GDS/PDS data and it is difficult to obtain information from the private sector. The number of treatments provided by private sector for IOTN 3.6 and above for the 12-17-year-olds is likely to be low.

In 2009, 22 former local health boards and NHS trusts in Wales were reorganised into seven LHBs and three special NHS trusts. A national review of the orthodontic services was carried out in Wales in 2009/10. ${ }^{7}$ The aim of this article is to detail orthodontic provision in Wales with particular attention to:

- The 12-17-year-old cohort population who may need orthodontic treatment

- The type of orthodontic activity undertaken

- Who is providing orthodontic care?

- The relative cost-efficiency of the orthodontic services

- Referral and access to orthodontic services

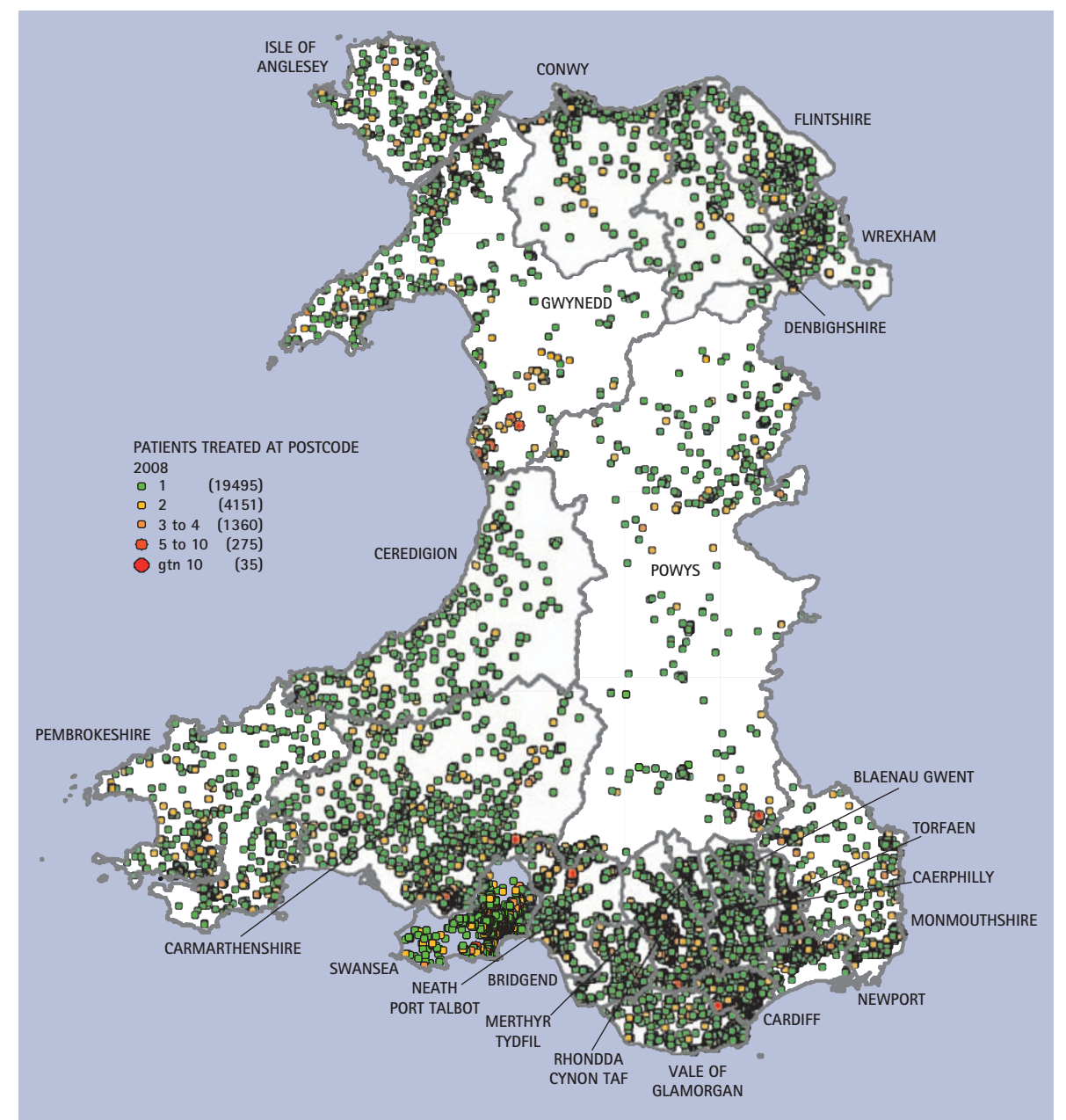

Fig. 1 Distribution of patient postcodes accessing orthodontic care in Wales Local authority population densities (individuals $/ \mathrm{km}^{2}$ ranked in order):

Cardiff 4,263; Newport 734; Torfaen 717; Blaenau Gwent 631; Caerphilly 614; Swansea 597; Rhondda Cynon Taff 547; Bridgend 530; Merthyr Tydfil 496; Vale of Glamorgan 365; Flintshire 343; Neath Port Talbot 307; Wrexham 261; Denbighshire 113; Monmouthshire 103; Conwy 99; Anglesey 96; Carmarthenshire 74; Pembrokeshire 74; Gwynedd 46; Ceredigion 44; Powys 25

- Contracting and performance management of the services

- Robustness of the orthodontic database.

\section{SUBJECTS AND METHODS}

\section{The 12-17-year-old cohort and estimation of orthodontic treatment need}

The mid-year population estimates for a cohort of 12-17-year-olds were provided by the Statistical Directorate Welsh Assembly Government for each of the 22 local authorities (LAs) for the year 2008. ${ }^{20}$ Orthodontic treatment need and uptake was estimated for this population.

Before reorganisation of the NHS in Wales in October 2009, there were 22 LHBs in Wales. These were co-terminus with LAs. Data were analysed at former LHB/LA level.

\section{Orthodontic activity in the GDS/PDS}

The orthodontic activity data for Wales were provided by the Dental Services (DS) department within the NHSBSA for contracted orthodontic activity in the year March 2008 to April 2009. Data were analysed using SPSS.

A subsample of 25 providers was further analysed to highlight the considerable variation in orthodontic activities provided by the GDS/PDS providers.

Patient postcodes and practice postcodes were used to calculate travelling distance. Inaccurate and unknown postcodes were proportionally distributed across the unitary authorities. Similarly no postcode data were available for the patients treated in the HDS and CDS clinics and these patients were also distributed proportionally across unitary authorities served by those clinics. 


\section{Relative cost-efficiencies of the orthodontic services}

Data were available on the relative costs of the orthodontic services in the GDS/PDS. Information regarding the relative costs of orthodontic provision in the HDS and CDS was collected using a questionnaire. The estimated costs of treatment for the salaried services were estimated from the salaried costs for all staff in the hospital/ community clinic plus estimated material/ capital costs of $£ 400$ for each active course of orthodontic treatment.

\section{RESULTS}

\section{The 12-17-year-old cohort and estimation of orthodontic treatment need}

As in any country or region, areas are often broken down into administrative regions and in Wales there were 22 LAs which were co-terminus with 22 former LHBs. After re-organisation of the NHS in Wales in 2009, there are now seven LHBs responsible for orthodontic provision in their respective areas (Table 1, Fig. 1).

It was estimated that there was a cohort of 38,464 children in Wales and $30 \%$ of this cohort may need and demand orthodontic care (provided by the NHS) sometime between 12 and 17 years of age. Therefore, orthodontic provision should potentially be available for 11,539 children across Wales, which could be provided by the GDS/PDS, HDS and CDS (Table 1).

In terms of service provision, there were $8,991(78 \%)$ individuals treated in the GDS/PDS, 1,620 (14\%) in the hospital services and $420(3.6 \%)$ in the community dental services. With the estimated treatment demand based on need $(11,539$ children), there could be a potential shortfall in orthodontic treatment for 508 (4.4\%) children within NHS provision.

In 2008/09 there was considerable variation in the orthodontic provision across 22 former LHBs in Wales. In 8 out of the 22 former LHBs, more than $30 \%$ of the 12-17-year-old population was treated. In four former LHBs, less than $20 \%$ of the $12-17$-year-old population was treated. The highest proportion of the 12-17-year-old population was treated in Cardiff (41\%) and the fewest in Flintshire (14\%).

\begin{tabular}{|c|c|c|c|c|c|c|c|c|c|c|c|}
\hline \multirow[b]{2}{*}{ Activity } & \multicolumn{11}{|c|}{ Patient age (years) } \\
\hline & 0 to 9 & 10 & 11 & 12 & 13 & 14 & 15 & 16 & 17 & $\begin{array}{l}18 \text { or } \\
\text { over }\end{array}$ & Total \\
\hline $\begin{array}{l}\text { Assess and } \\
\text { accept }\end{array}$ & 247 & 395 & 1,072 & 1,932 & 1,996 & 1,511 & 957 & 532 & 273 & 76 & 8,991 \\
\hline $\begin{array}{l}\text { Assess and } \\
\text { review }\end{array}$ & 3,868 & 2,310 & 2,876 & 2,828 & 2,137 & 1,413 & 918 & 560 & 338 & 153 & 17,401 \\
\hline $\begin{array}{l}\text { Assess and } \\
\text { refuse }\end{array}$ & 60 & 72 & 197 & 365 & 458 & 397 & 346 & 225 & 176 & 45 & 2,341 \\
\hline $\begin{array}{l}\text { Treatment } \\
\text { completed }\end{array}$ & 127 & 124 & 258 & 612 & 1,071 & 1,273 & 1,116 & 758 & 386 & 345 & 6,070 \\
\hline $\begin{array}{l}\text { Treatment } \\
\text { abandoned }\end{array}$ & 4 & 13 & 24 & 50 & 65 & 62 & 59 & 67 & 40 & 33 & 417 \\
\hline $\begin{array}{l}\text { Treatment } \\
\text { discontinued }\end{array}$ & 5 & 6 & 10 & 34 & 38 & 34 & 31 & 35 & 15 & 7 & 215 \\
\hline Repairs & 4 & 11 & 80 & 165 & 172 & 179 & 107 & 50 & 28 & 13 & 809 \\
\hline $\begin{array}{l}\text { Regulation } 11 \\
\text { appliances }\end{array}$ & 3 & 8 & 22 & 63 & 102 & 129 & 99 & 49 & 49 & 29 & 553 \\
\hline Total & 4,318 & 2,939 & 4,539 & 6,049 & 6,039 & 4,998 & 3,633 & 2,276 & 1,305 & 701 & 36,797 \\
\hline $\begin{array}{l}\text { Units of ortho- } \\
\text { dontic activity }\end{array}$ & 4,919 & 10,686 & 25,649 & 43,897 & 44,649 & 33,684 & 21,447 & 11,997 & 6,269 & 1,956 & 205,153 \\
\hline $\begin{array}{l}\text { Number } \\
\text { of patient } \\
\text { identities }\end{array}$ & 3,999 & 2,784 & 4,275 & 5,640 & 5,654 & 4,730 & 3,427 & 2,181 & 1,249 & 689 & 34,628 \\
\hline
\end{tabular}

\section{Table 3 Estimated relative costs per treated case for clinics in the salaried services}

\begin{tabular}{|c|c|c|c|}
\hline \multicolumn{2}{|l|}{ HDS } & \multicolumn{2}{|l|}{ CDS } \\
\hline Area & Cost $(\mathrm{t})$ & Area & Cost (E) \\
\hline Abertawe Bro Morgannwg 1 & 2,268 & Betsi Cadwaladr & 2,133 \\
\hline Abertawe Bro Morgannwg $2^{* * *}$ & 2,534 & Cwm Taf 1 & 1,454 \\
\hline Anuerin Bevan 1 & 1,674 & Cwm Taf 2 & 1,405 \\
\hline Aneurin Bevan $2^{+}$ & 1,596 & Cwm Taf 3 & 1,584 \\
\hline Betsi Cadwaladr 1 & 2,518 & Cardiff and Vale & 1,467 \\
\hline Betsi Cadwaladr 2 & 2,883 & Average & 1,609 \\
\hline Betsi Cadwaladr $3^{+}$ & 2,593 & & \\
\hline Cardiff and Vale ${ }^{*+}$ & 2,012 & & \\
\hline Cwm Taf $^{+}$ & 2,150 & & \\
\hline Powys ${ }^{* * *}$ & 972 & & \\
\hline Average & 2,120 & & \\
\hline
\end{tabular}

\section{The type of activity undertaken}

The categories of orthodontic activity undertaken are shown using the vital signs data provided by the dental services NHSBSA (Table 2). In 2008/09 a total of 28,733 individuals were assessed of whom 17,362 were between 12 to 17 years of age. This is 51\% greater than the estimated 30\% level of demand based on need from the 12-17-year-olds.
There is a large proportion of 'assess and review' undertaken below the age of ten (Table 2). On closer investigation this activity was found to be mainly (although not exclusively) associated with practitioners who did not provide orthodontic active appliance treatment. This also seems related to a higher number of patients than would normally be expected arising from the same postcode. This early assessment 
was seen particularly in certain former LHBs (Gwynedd, Powys, Pembrokeshire, Swansea, Cardiff, Rhondda Cynon Taf and Torfaen) but not generalised across providers.

\section{Who is providing orthodontic care?}

Out of 135 GDS/PDS orthodontic contracts, 62 practitioners provided less than 50 treatments per year and there were 2 contracts with more than 600 treatments per year (Table 1). Active orthodontic treatment was undertaken by 108 performers/ providers in all services and in 27 GDS/ PDS contracts no active orthodontic treatment was provided (only orthodontic assessments). Although contracts are issued to providers and provider performers it is not always known who is actually providing the treatment. It is known that there are a number of orthodontic therapists $(<6)$ working in both the GDS/PDS and HDS.

Outlier practitioner behaviour was also highlighted in relation to reported 'repairs'. The majority of practitioners in Wales did not claim for repairs $(2.2 \%$ of total activity). However, the greatest number of repairs arose from practitioners within the same premises but with a different contract number. The highest proportion of repairs was claimed from South West Wales (Swansea (47\%), Carmarthenshire (37\%), Cardiff (10\%) and Gwynedd (3\%)).

\section{Relative cost-efficiency of the orthodontic services}

A total of 34,628 patients attended the GDS/PDS for orthodontic care in the year 2008/09. The 36,797 treatment activities attracted 205,153 UOAs with an average UOA cost of $€ 62$ (range £58 to £74) representing a total spend of $£ 12,718,370$ on GDS/PDS orthodontic provision in Wales.

Based on the completed questionnaire from the HDS and CDS, the estimated relative costs of orthodontic treatment were derived for each salaried orthodontic provider (for example, staff salaries - top of scale, plus materials) (Table 3). The average estimated cost for a case treated in the HDS was $£ 2,120$ (range £972 to £2,883) compared with $£ 1,609$ (range $£ 1,405$ to $£ 2,133$ ) for the CDS. The cost per treatment in the GDS/PDS ranged from £1,364 to £1,628. Three to eighty-five percent of the patients treated in the HDS were adults.

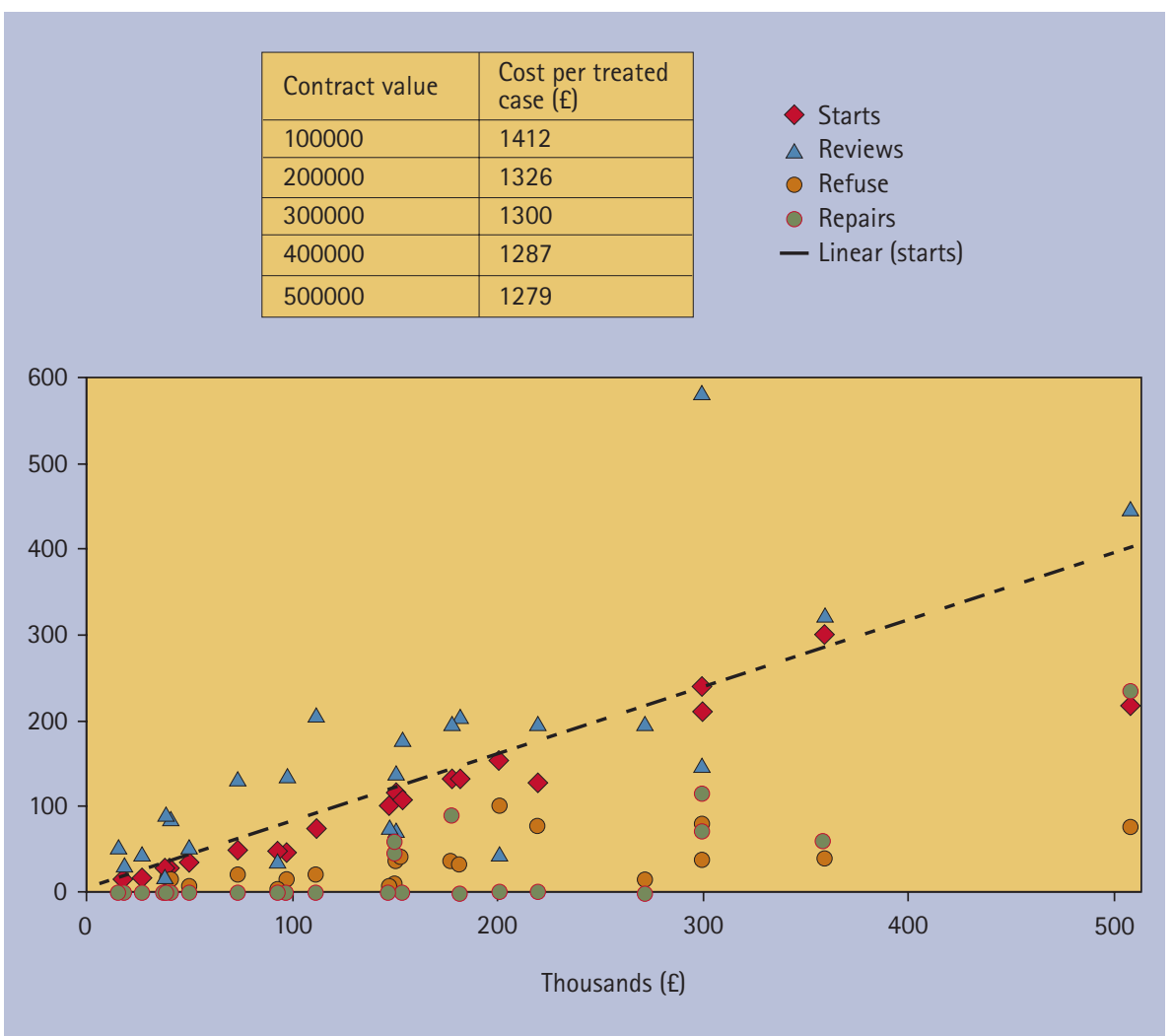

Fig. 2 A sample of 25 practitioners working in the GDS/PDS with different size of orthodontic contracts

\section{Referral and access to orthodontic services}

Postcode data were available from $68 \%$ of the sample. There seems to be considerable cross border patient flow between former LHBs. Five former LHBs provided significant orthodontic care for others: Gwynedd supplied Isle of Anglesey and Conwy, Carmarthenshire supplied Pembroke and Ceredigion, Swansea supplied Neath Port Talbot and Carmarthenshire, Cardiff supplied Vale of Glamorgan, Rhondda Cynon Taf and Caerphilly, and Newport supplied Monmouthshire, Torfaen and Caerphilly.

Using the postcode data for orthodontic providers and patients, the average distance travelled from the patients home address to the orthodontic provider was 8.9 miles (range 0 to 175.5 miles). The distribution of patients' postcodes across Wales has been presented in Figure 1.

Distances greater than 50 miles $(0.3 \%$ of all travel) were generally undertaken by patients residing in Carmarthen, Ceredigion, Pembrokeshire and Powys. The greatest recorded distance travelled was 175.5 miles from Gwynedd to Cardiff for two individuals.

\section{Contracting and performance management of the services}

To illustrate variation in orthodontic activity 25 contracts are displayed (Fig. 2). The contract worth £360,000 generated 302 treatments, 324 assess and reviews, 40 assess and refuse and 61 repairs. Another contract for £510,000 generated 219 treatments, 448 reviews, 77 refusals and 235 repairs. The $£ 510,000$ contract is an outlier compared to the other 24 contracts in terms of number of patients treated. The $£ 300,000$ contract is an outlier in terms of the number of reviews, 582, compared with 212 treatment starts. Out of the 25 contracts only 8 claimed for repairs and in one contract the repairs outnumbered the treatment starts.

\section{Robustness of the orthodontic database}

There is a discrepancy between the number of treatment starts $(8,991)$ and the number of treatments completed $(6,070)$. This discrepancy amounts to $32.5 \%$ of documented activity. The number of abandoned/discontinued amounted to $632(7 \%)$ of all treatments.

\section{DISCUSSION}

The following limitations need to be considered when interpreting the results: 
- Data collected from the HDS and CDS were self-reported and relative cost efficiencies were based on questionnaire and assumptions as stated on Table 3. Moreover, types of patients, level of involvement in teaching/training and treatment complexities vary between the salaried services

- Estimates of treatment need and demand were based on the crosssectional child dental survey and population estimates for 12-17-year olds that have their own limitations.

Despite the limitations discussed above, there seem to be considerable inefficiencies within the orthodontic service provision in Wales. Issues arising from the GDS/PDS data analysis and self-reported salaried service data could be largely divided into the following broad categories;

- Referral management (normative need, orthodontic activity)

- Workforce and skill mix (who is providing orthodontic care?)

- Service provision, commissioning and performance management

- Robustness of the orthodontic database

- Regulatory framework.

\section{Referral management (normative need, orthodontic activity)}

The main purpose of referral to an orthodontic practitioner is currently determined using the IOTN criteria.

There is evidence from the GDS/PDS data that there were relatively high numbers of referrals below the age of nine, 'assess and refuse' and 'assess and review' (Table 2). This indicated that many referrals to the orthodontic services were inappropriate or ill-timed. There is also anecdotal evidence that many patients are referred to multiple orthodontic providers.

The vast majority of orthodontic treatment was undertaken between 11 and 15 years of age. In 1987/88 the proportion was $71 \%$ and $60.3 \%$ in $2008 / 09$. In $1987 / 88,10 \%$ more cases were being treated at 11 years of age (Fig. 3). The difference in proportions may result from the effects of sampling 1,010 prior approval cases in 1987/88 compared with all 8,991 cases entering treatment in $2008 / 9 .^{8,21}$ In a previous report of orthodontic treatment in Wales, 67\% of

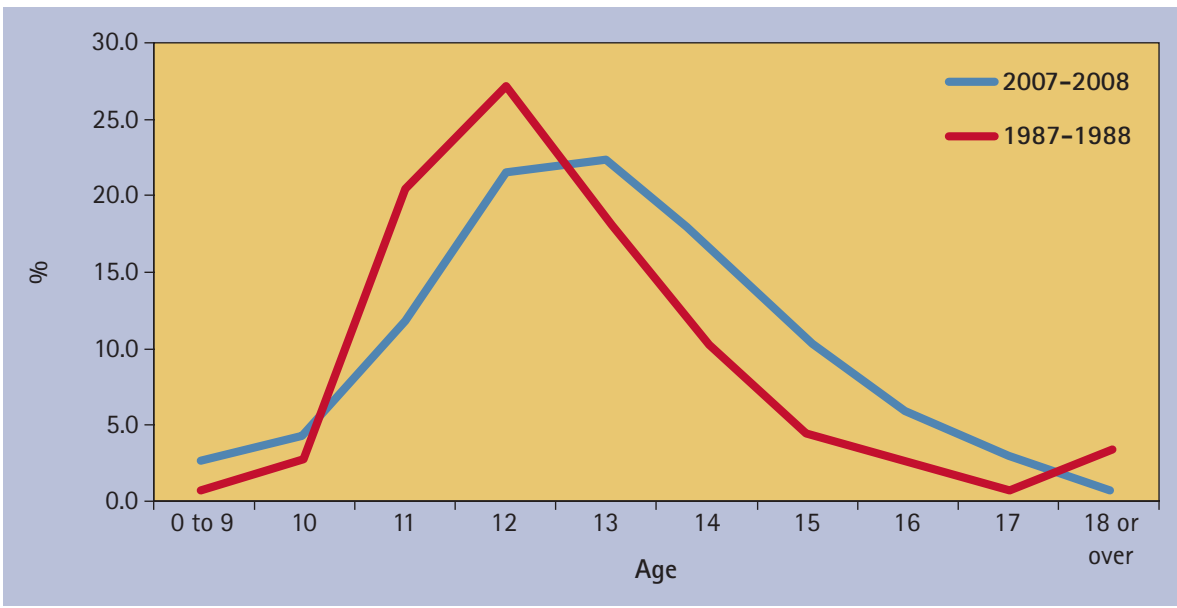

Fig. 3 Comparison of age at commencement of orthodontic treatment in the GDS/PDS 1987/8 (prior approval cases only) and 2008/9 (1,010 and 8,991 cases respectively) $)^{3,21}$

patients were treated between the ages of 14 and 17 years of age, which is considerably higher than that reported elsewhere. ${ }^{11}$ This discrepancy may be due to sampling whereby the practitioners were asked to identify 100 consecutively treated cases (which may have included private treatments) 11 compared to other treatments purely undertaken under NHS conditions. ${ }^{7,8}$ There is a tendency in the UK to treat patients when the canines and premolars are erupting and this is usually after 11 years of age. There does not seem to be a dramatic shift or delay in the timing of treatment under the new orthodontic contract.

A robust referral management system should be introduced to deter inappropriate referrals. Many primary care trusts in England have introduced central referral management centres where referrals are scrutinised by a clinician or an administrator before rejecting or redirecting referrals to appropriate providers. Alternatively, strict referral criteria and a standardised referral pro forma could be introduced and compliance scrutinised through audit process. Targeted education and management of providers and referrers is required to ensure compliance with the referring system in place. Simply distributing referral guidance to referring practitioners will not be effective. Advantages and disadvantages of each referral system should be analysed before their implementation. In Wales, some regional managed clinical networks (MCNs) are working towards introducing a referral management system in orthodontics.

\section{Workforce and skill mix (who is providing orthodontic provision?)}

The orthodontist:population ratio is often quoted as the number of orthodontists required to treat the child population. ${ }^{19}$ As opposed to active whole time equivalents, this is a very imprecise way of estimating the workforce. In several reports it has been suggested that England and Wales falls short of other countries. One report in 2002 suggested there was a ratio of 1 orthodontist to 300 12-year-olds (based on 30\% need) in England and Wales compared with 1:82 in Iceland. ${ }^{19}$ Another report in 2009 suggested there is 1 orthodontist to 198 12-year-olds compared to Iceland's ratio of $1: 116 .^{22}$ The data is perhaps not sufficiently robust and does not take into account the amount of time worked and support of additional staff.

The precise requirement for orthodontists depends on how the orthodontic service is organised. The current data in Wales suggest that there are 108 practitioners providing active care. Therefore the practitioner to 12-year-old patient ratio is 1 practitioner to 107 12-year-olds (30\% need). The number of practitioners needed to treat the 12-17-year-old cohort depends on the volume of treatment undertaken. If the average caseload was 150 cases a year, 79 whole time equivalent practitioners would be needed and for 300 cases a year, 39 whole time equivalent (WTE) practitioners would be sufficient (Table 1). The orthodontic workforce is a mixture of fulland part-time staff consisting of orthodontic therapists and dentists with a special interest (DwSI) in orthodontics. Assuming an individual caseload of 150-300 cases a 
year, it is likely that a workforce between 39 and 79 WTE practitioners is sufficient to deliver required orthodontic services in Wales. A smaller number of contracts and practitioners would make the service easier to manage/monitor and may create a culture of providing high quality orthodontic care. However, the geographical spread of the practice locations may result in longer travelling distance for some patients. In instances of low population densities (for example Powys, Fig. 1) there are several options for the provision of treatment: the patient can travel to a specialist orthodontist, an orthodontist can travel to rural communities providing care on a 4-6 week basis and finally the utilisation of certified dentists with a specialist interest in orthodontics.

There are only a small number of orthodontic therapists currently working in Wales, however, the number is likely to increase and may lead to restructuring of the orthodontic services. For instance one orthodontist and four orthodontic therapists could undertake an annual caseload in excess of 600 treatment starts a year. As the salary of an orthodontic therapist is reportedly lower than an orthodontist, there should be some cost saving in the delivery of orthodontic care. The addition of orthodontic therapists may require redesigning some existing premises and rethinking the distribution of orthodontists. The number of therapists required depends on their speed in the tasks performed and this can vary considerably as it does with orthodontists.

\section{Service provision, commissioning and performance management}

In 2006, orthodontic contracts were offered to those providers who were already providing orthodontic services in the area under the old 'fee per item' system. Hence, the location and level of orthodontic services were not based on local needs assessment. This resulted in the uneven distribution of the GDS/PDS orthodontic budgets between the LHBs and as a consequence, in some areas there was a cross-border flow of patients. The crossborder flow of patients between the LHBs is substantial enough to warrant planning and service design at regional level.

Inequity of access to orthodontic care with low uptake in districts of high deprivation has been reported in the UK. ${ }^{18,23}$ It seemed reasonable to assume that LAs with more deprived areas will have a higher level of decayed teeth and a lesser proportion of children would demand and access orthodontic care. However, there seemed to be no such association when data were analysed at LA level (Table 1). For example Merthyr Tydfil has a much higher level of decay in children compared to those in Powys, Flintshire and Conwy, ${ }^{24}$ while orthodontic treatment uptake by children in Merthyr Tydfil is higher than those in Powys, Flintshire and Conwy. This may be because of a combination of various factors such as availability of local providers, variation in dental status criteria set by local providers, orthodontic treatment through private arrangements and accuracy of reported data. In a previous report of the orthodontic services it was noted that there was a greater number of patients treated with a lower objective need in high volume treatment areas and this should be monitored..$^{25}$

Various factors such as accuracy of postcodes, agreement between neighbouring LHBs for service provision, historical service provision and viability of service provision in rural areas need to be considered when interpreting data related to travelling distance and cross-border flow of patients. There is anecdotal evidence that patients will avoid certain practitioners, follow practitioners or even keep with a practitioner when they move, as they are happy with the care they receive. Also individuals will often seek care from a practice that is convenient to fit in with their personal life/social activities. The increase in travelling distance for patients in Carmarthen, Ceridigion and Pembrokeshire appears to be associated with rurality and pattern and cost of orthodontic provision in west Wales.

There is also a wide variation in cost per treated case in hospital and community services and the variation in costs is sensitive to the number and mix of staff employed and salary of the employees. It is difficult to obtain an accurate cost for orthodontic treatment as there are significant subsidies provided to all services. However, estimates for the cost of orthodontic treatment in hospital and community services are not too far from the average cost in the GDS/ PDS of $£ 1,381$ considering their reported different roles. The different caseloads in each of the hospital settings will have an impact on the planning of the orthodontic services as treatment of a high proportion of adult patients will affect services available for children. Local health boards should develop strict criteria for provision of adult orthodontics so that rising demand for adult orthodontics does not affect the level of provision for children.

There seems to be less than adequate monitoring and performance management of orthodontic contracts in Wales. LHBs seem to have focused their orthodontic contract management solely on delivery of annual contracted UOAs. There seems to be no monitoring on what has been delivered clinically and the outcome of orthodontic treatment has not been fully documented. This is surprising considering recent reports indicating significant variation in clinical outcomes. ${ }^{8,11-13}$ Excessive 'assessment and reviews', non-completion of required data on FP170W, unknown IOTN status of many cases under treatment and a larger than expected discrepancy between 'treatment starts' and 'treatment completes' seem to be common in most contracts. In 2008/09 there were 27 orthodontic contracts that undertook no active appliance treatment and only provided orthodontic assessments. Recently the Welsh government has issued interim guidance to LHBs on management of orthodontic contracts. ${ }^{26}$ The guidance has provided some key performance indicators (KPIs) for a PDS orthodontic contract. One of the KPIs is that orthodontic contracts should, as a minimum, deliver a number of treatments equal to contracted UOAs divided by 2.5 . This assumes that one person will start treatment for every 2.5 patients seen by an orthodontic provider. To achieve this target, orthodontic providers will need to ensure that they receive appropriate referrals. Since publication of the guidance, some LHBs in Wales have started specifying the number of treatments to be delivered annually in a renewed or new orthodontic contract.

In Wales, the GDS/PDS orthodontic expenditure was around £12.7 million. In terms of UOA rate, there seems to be wide variation between providers, with some contracts set up with extremely high UOA rates of $€ 74$. Although factors such as rurality, lack of alternate providers and 
varied service specification could account for some variation in UOA rate, the range of UOA rates from $£ 58$ to $£ 74$ seems too wide. Currently NHS orthodontic contracts are highly sought after by the providers and competitive tendering or re-negotiation with existing high UOA rate providers could create extra capacity in the system. For example if all contracts were set at £58/UOA, 12.7 million would buy 218,965 UOAs that in turn should deliver at least 9,732 (218,965/22.5) treatments per year in the GDS/PDS.

The consultant orthodontic survey reported re-treatment rates as being $12 \%$ and 5.6\% in 1985 and 1995 respectively. ${ }^{27}$ No available data for re-treatment for the GDS/PDS is available, although it has been reported that 3 out of 10 patients treated in the HDS and 6 out of 10 patients in the GDS were less likely to achieve satisfactory outcomes and as a result there may be significant numbers of patients (600 to $1,100)$ requiring and obtaining re-treatment each year in Wales within the GDS/ PDS/HDS. ${ }^{9}$ The re-treatment rate needs to be monitored in all services as this can have a significant impact in terms of cost and capacity of care.

\section{Robustness of the orthodontic database}

In Wales, the GDS/PDS orthodontic activity data on each practitioner is collected via the FP170W by the NHSBSA and provided to the relevant LHBs through interim and annual reports. Robustness of this database depends on completion of all required fields in the form by the practitioners. There is evidence from the available GDS/PDS dataset that all required fields, including IOTN scoring, are not completed by many practitioners despite being a mandatory requirement. There also seems to be no system in place that would 'bounce back' forms that are not completed fully. Moreover, LHBs with new responsibility for dental contracts since 2006 do not seem to be monitoring the quality and extent of data available for them for contract management and their focus seems to be just delivery of contracted UOAs.

If all relevant fields on FP170W were completed fully, the GDS/PDS dataset would be good enough for detailed management of contracted services and equity audit for future planning purposes. There is no incentive of the practitioners to complete the second FP170W. Moreover, there seems to be no mechanism in place to highlight non-completion of the second FP170W after a certain period of time. It can be argued that improvement in the data collection will only occur if a proportion of the contracted sum was held back until an agreed level of compliance was reached.

In terms of monitoring orthodontic treatment outcomes, practitioners are required to record the peer assessment rating (PAR) score of 20 cases and 10\% of remaining orthodontic cases. However, there is no central database of PAR scores of treated cases and consequently the quality of treatment provided is largely unknown. LHBs can request PAR scores from the orthodontic performers and providers in their area to monitor treatment outcomes directly or through MCN. It is generally accepted that PAR scoring should be carried out by an independent and calibrated person. If another quality measure such as the Index of Complexity, Outcome and Need (ICON) was introduced, treatment outcomes could be performed at the time of 'debond' and entered on the FP170W, as this measure can be performed on the patient without waiting for dental casts. ${ }^{7,28}$

The HDS and CDS database system is archaic and has very limited benefits for planning purposes. Fundamental information such as annual number of treatments and types of treatments provided by a salaried service are not available. There seems to be a need for change in the HDS and CDS data system so that data comparable to the GDS/PDS is collected.

\section{Regulatory framework}

Dental regulations require all orthodontic contracts to be time limited PDS arrangements. However, many orthodontic contracts in Wales were set up as GDS contracts which are not time limited. These contracts need to be re-negotiated as PDS agreements so that they are underpinned by appropriate regulations.

Amendments in the dental regulations will/may be required to clarify subsequent issues related to NHS orthodontic contracts.

Currently the PDS agreements (Wales) regulation does not allow partnerships in the PDS contracts. Establishing, maintaining and modernising an orthodontic practice is expensive and partnerships will reduce the risk for an individual practitioner/provider. Consideration should be given to incorporate a clause to clarify that the PDS contracts can be established with partnerships. However, partnership change during the contract period should be approved by the LHB.

The PDS regulation is unclear on responsibility for completion of ongoing treatment when an orthodontic contract comes to an end for various reasons. Having received 21 UOAs and associated payments on starting treatment, it is not unreasonable to make the provider/practitioner who started treatment responsible for completion of all ongoing treatments. This is beneficial to patients in terms of continuity of care.

Although the majority of NHS orthodontics is provided to children, adults are also eligible for orthodontic treatment. With rising demand for adult orthodontics, PDS regulation should specify which groups of adult patients, if any, are eligible for NHS orthodontics.

It is imperative that orthodontic care is undertaken to the highest possible quality. Provided the patient was compliant, there is a strong argument to provide orthodontic care through the GDS/PDS once and re-treatments be undertaken by the practitioner who originally provided the treatment at their own expense if proven that the original treatment was not satisfactory.

To improve compliance with completion of all fields in the FP170W and second FP170W when treatment is completed/ abandoned/discontinued, LHBs should be allowed to hold back a certain amount of annual contracted sum until data completion from a provider is satisfactory.

LHBs may also find it helpful if the regulation specified that orthodontic contracts should stipulate a minimum number of treatments to be delivered annually. Similarly independent scoring outcome monitoring, rather than self-scoring PAR, should be required to ensure the delivery of quality treatments.

\section{CONCLUSION}

With the rising demand for orthodontic treatment, it is important that orthodontic services are competitive, highly 
efficient and provided on the basis of need. Performance management of the orthodontic services should focus on the number of successful orthodontic treatments delivered annually. The personal dental services (PDS) orthodontic contracts will need to be modified accordingly.

The authors would like to acknowledge the Dental Division, Welsh Government for allowing us to use the data and reproduce graphs/tables from the Orthodontic Subgroup Report. In addition the authors appreciate the contributions from Steve Lucarotti, (Senior Statistician), NHS Dental Services; British Orthodontic Society; Welsh Consultant and Community Groups; Maria Morgan and Nigel Blewitt (Dental Public Health Unit, Cardiff Dental School).

1. Shaw W C, Richmond S, Kenealy P M, Kingdon A, Worthington $\mathrm{H}$. A 20-year cohort study of health gain from orthodontic treatment: psychological outcome. Am J Orthod Dentofacial Orthop 2007; 132: 146-157.

2. Liu Z, McGrath C, Hägg U. The impact of malocclusion/ orthodontic treatment need on the quality of life. A systematic review. Angle Orthod 2009; 79: 585-591.

3. Bollen A M. Effects of malocclusions and orthodontics on periodontal health: evidence from a systematic review. J Dent Educ 2008; 72: 912-918.

4. Audit Commission. Dentistry, primary dental services in England and Wales. London: Audit Commission, 2002. Online article available at http://www. audit-commission.gov.uk/SiteCollectionDocuments/ AuditCommissionReports/NationalStudies/ReportDentistry.pdf (accessed June 2011).

5. Bennett H. An overview and needs assessment of NHS primary care orthodontics: Mid and West Wales region. Wellbeing and Local Government Committee, 2010. Online article available at http:// www.assemblywales.org/hwlg_3_-15-10-p4_ annex_a_national_public_health_wales_.pdf (accessed January 2012).

6. Stuart G. Early day motion 974. Orthodontic care. Parliamentary motion. Online article available at http://www.parliament.uk/edm/2006-07/974 (acessed June 2011).

7. Welsh Assembly Government. Task and finish report, orthodontic sub-group, September 2010. Online article available at http://wales.gov.uk/docs/phhs/ publications/101109reporten.pdf (accessed June 2011).

8. Richmond S, Shaw W C, Stephens C D, Webb W G, Roberts C T, Andrews M. Orthodontics in the general dental service of England and Wales: a critical assessment of standards. Br Dent J 1993; 174: 315-329.

9. Richmond $\mathrm{S}, \mathrm{O}^{\prime}$ Brien K. Health gain in orthodontics: a comparison of the general dental services and the hospital service in England and Wales. Community Dent Health 1996; 13: 128-32.

10. Turbill E A, Richmond S, Wright J L. A closer look at General Dental Service orthodontics in England and Wales. I: Factors influencing effectiveness. Br Dent J 1999; 187: 211-216.

11. Richmond S, Durning P, Phillips $C$, Dunstan $F_{\text {, }}$ Daniels C, Leahy F. Measuring the cost, effectiveness and cost-effectiveness of orthodontic treatment. Part 1. Orthodontics 2004; 1: 255-262.

12. Richmond S, Dunstan F, Phillips C, Daniels $C_{\text {, }}$ Durning $P$, Leahy F. Measuring the cost, effectiveness, and cost-effectiveness of orthodontic care. World J Orthod 2005 ; 6: 161-70

13. Dunstan F, Richmond S, Phillips C, Durning P. League tables for orthodontists. Eur J Orthod 2008; 30: 636-640

14. Department of Health. Strategic commissioning of primary care orthodontic services. London: Department of Health, 2006. Gateway approval reference number 7105. Available online at http:// www.dh.gov.uk/en/Publicationsandstatistics/ Publications/PublicationsPolicyAndGuidance/ DH_4139176 (accessed 24 January 2012).

15. National Assembly for Wales. The National Health Service (general dental services contracts) (Wales) Regulations 2006; Statutory Instruments. 2006; No 490 (W.59).

16. National Assembly for Wales. The National Health Service (personal dental services agreements) (Wales) Regulations 2006. Statutory Instruments. 2006; No 489 (W.58).
17. Chestnutt I, Pendry L, Harker R. The orthodontic condition of children from children's dental health in the United Kingdom, 2003. London: Office for National Statistics, 2004.

18. O'Brien K. Orthodontic interactions: the relationships between the orthodontic services in England and Wales. Br J Orthod 1991; 18: 91-98.

19. Robinson P G, Willmot D, Parkin N, Hall A C. Report of the orthodontic workforce survey of the United Kingdom February 2005. University of Sheffield, 2005. Online article available at http://www.parliament.uk/deposits/depositedpapers/2010/DEP20101780.pdf (accessed January 2012).

20. Statistical Directorate. Mid-year population estimates (1991-2000), by local authority. Welsh Assembly Government, 2009.

21. Richmond $S$, Andrews M, Roberts C T. The provision of orthodontic care in the general dental services of England and Wales: extraction patterns, treatment duration, appliance types and standards. Br J Orthod 1993; 20: 345-50.

22. Kravitz A S, Treasure E T. Manual of dental practice, 2008. The Council of European Dentists, 2008. Online article available at http://www.bzaek.de/ fileadmin/PDFs/za/ZaeBA/EU_Manual_of_Dental_ Practice_CED_2008.pdf (accessed January 2012).

23. Morris $E$, Landes D. The equity of access to orthodontic dental care for children in the North East of England. Public Health 2006; 120: 359-363.

24. Welsh Oral Health Information Unit. Survey of 12 year olds oral health, 2008/09. Annual reports for childhood oral epidemiology programme. Cardiff: Cardiff University, 2009

25. Turbill E A, Richmond S, Wright J L. A critical assessment of high-earning orthodontists within the General Dental Sevices of England and Wales (1990-1991). Br J Orthod 1998; 25: 47-54.

26. Welsh Assembly Government. Interim guidance on management of NHS orthodontic contracts in primary dental care. March 2011.

27. Russell J I, Pearson A I, Bowden D E J, Wright J, O'Brien K D. The consultant orthodontic service 1996 survey. Br Dent J 1999; 187: 149-153.

28. Daniels $C$, Richmond S. The development of the index of complexity, outcome and need (ICON). J Orthod 2000; 27: 149-62. 